\title{
Serum Erythropoietin Level in Chronic Kidney Disease Patients with Anemia: A Baseline Study at Chittagong Medical College, Chittagong, Bangladesh
}

\author{
Mizanur Rahman ${ }^{1}$, Mahmudul Haque ${ }^{2}$, ASM Towhidul Alam ${ }^{3}$, Md. Nurul Amin ${ }^{4}$, \\ K. M. Huria Parveen ${ }^{5}$, Naila Al Mahmuda ${ }^{6}$, Md. Golam Abbas ${ }^{7,8, *}$ \\ ${ }^{1}$ Department of Biochemistry, Rangamati Medical College, Rangamati, Bangladesh \\ ${ }^{2}$ Department of Biochemistry, Chittagong Medical College, Chittagong, Bangladesh \\ ${ }^{3}$ Department of Biochemistry, Cox's Bazar Medical College, Cox's Bazar, Bangladesh \\ ${ }^{4}$ Department of Anesthesiology, Sylhet Women's Medical College, Sylhet, Bangladesh \\ ${ }^{5}$ Department of Biochemistry, Dhaka Medical College, Dhaka, Bangladesh \\ ${ }^{6}$ Graduate School of Medical Sciences, Kanazawa University, Kanazawa, Ishikawa, Japan \\ ${ }^{7}$ Department of Molecular Neuroscience and Integrative Physiology, Graduate School of Medical Sciences, Kanazawa University, Kanazawa, \\ Ishikawa, Japan \\ ${ }^{8}$ Infectious Diseases Hospital, Dhaka, Bangladesh
}

\section{Email address:}

abbasgolam@yahoo.com (Md. G. Abbas)

*Corresponding author

\section{To cite this article:}

Mizanur Rahman, Mahmudul Haque, ASM Towhidul Alam, Md. Nurul Amin, K. M. Huria Parveen, Naila Al Mahmuda, Md. Golam Abbas. Serum Erythropoietin Level in Chronic Kidney Disease Patients with Anemia: A Baseline Study at Chittagong Medical College, Chittagong, Bangladesh. American Journal of Clinical and Experimental Medicine. Vol. 4, No. 2, 2016, pp. 20-25. doi: 10.11648/j.ajcem.20160402.12

Received: February 11, 2016; Accepted: February 24, 2016; Published: March 17, 2016

\begin{abstract}
Chronic kidney disease (CKD) is a serious condition associated with premature mortality, decreased quality of life, and increased health-care expenditures. A failure to produce sufficient Erythropoietin (EPO) accounts for the moderate to severe anemia observed in chronic kidney disease. Decreased EPO production is attributed to destruction of renal production sites. A cross-sectional descriptive study was designed for determination of erythropoietin level in chronic kidney disease patients with anemia. At the same time measurement of serum iron and serum ferritin to establish anemia. Serum concentration of erythropoietin was the parameter taken to evaluate the kidney status. This study was carried out in the Nephrology ward, Chittagong Medical College Hospital (CMCH), Chittagong, Bangladesh during the period of January 2012 to December 2012. Total Sixty Patients having hemoglobin level $<11 \mathrm{gm} / \mathrm{dl}$ and serum creatinine $>3 \mathrm{mg} / \mathrm{dl}$ taken as a case of chronic kidney disease with anemia. Mean Hemoglobin level found 8.67gm/dl $[ \pm 1.39 \mathrm{SD}$ (standard deviation), Serum creatinine level found $8.21 \mathrm{mg} / \mathrm{dl}( \pm 3.25 \mathrm{SD})$, Serum erythropoietin level found $2.67 \mathrm{miu}$ (mili international unit) $/ \mathrm{ml}$ ( $\pm 2.36 \mathrm{SD})$, Serum iron level found $13.78 \mu \mathrm{g} / \mathrm{dl}( \pm 2.58 \mathrm{SD})$. Serum ferritin level found $73.35 \mathrm{ng} / \mathrm{mL}( \pm 26.81 \mathrm{SD})$. It is also observed that Pearson's correlation coefficient $(r)$ between erythropoietin and hemoglobin is $-0.190(\mathrm{r}=0.036, \mathrm{p}$ value $=0.145)$, which is not significant. Correlation coefficient between erythropoietin and creatinine is $-0.082(\mathrm{r}=0.007 \mathrm{p}$ value $=0.532)$, which is not significant. Correlation coefficient between erythropoietin and iron is $0.021(\mathrm{r}=4.549$, $\mathrm{p}$ value $=0.872)$, which is not significant but shows weakly positive correlation. Correlation coefficient between erythropoietin and ferritin is $0.005(\mathrm{r}=2.723 \mathrm{p}$ value $=0.968)$ which is not significant but also shows weakly positive correlation.
\end{abstract}

Keywords: Erythropoietin, Iron, Ferritin, Chronic Kidney Disease 


\section{Introduction}

CKD is defined as kidney damage with or without GFR (Glomerular filtration rate) manifested as either pathological abnormalities or markers of kidney damage including abnormalities in composition of blood or urine, renal imaging findings and a GFR less than $60 \mathrm{ml} / \mathrm{m} .1 .73 \mathrm{~m}^{2}$. This broad definition includes patients with or without symptoms of kidney disease. In USA, diabetes is the number-one cause of chronic kidney failure, accounting for more than $44 \%$ of new cases of CKD each year. In 2010, the national estimates on diabetes indicated that 25.8 million people $(8.3 \%$ of the population) in the United States have diabetes. In 2010, an estimated 79 million Americans were diagnosed with prediabetes, a condition with blood glucose levels or A1c levels elevated but not yet high enough to be diagnosed as diabetic. Approximately 215,000 people 20 years old and younger have diabetes. This represents $0.26 \%$ of all people in this age group [1].

The top two causes of CKD in adults are diabetes and hypertension. Both conditions can be medically managed and mitigated; such intervention is crucial to reducing individuals' risk of developing CKD. The causes in children vary by age; those from birth to early teens usually have cystic, hereditary, or congenital disease. From 15-19 years, the cause of CKD is most often glomerulonephritis. More than 25 million Americans have diabetes, and an approximately 73 million Americans have hypertension. All are at risk of developing CKD. CKD can lead to numerous health problems, such as anemia, cardiac complications, bone loss, and death [2].

EPO is the primary regulator of erythropoiesis, stimulating the proliferation and differentiation of erythroid precursor cells in the bone marrow. In mammals, the fetal liver produces nearly all the hormone. In adults, hepatic production drops to under $10 \%$ and renal secretion accounts for over $90 \%$. The production site is believed to be the proximal renal tubular cells or the peritubular capillary endothelial cells of the renal cortex and other medulla [3].

The ferritin molecule consists of a protein shell MW (Molecular weight) 450,000 and a core of iron. High concentrations are found in liver cells and in erythrocyte recycling centers RE (Reticulo Endothelial) cells of the liver, spleen and bone marrow. In these tissues, ferritin serves as the body's principle storehouse for surplus iron, protecting against the toxic effects of excess and maintaining a readily mobilized reserve for erythropoiesis [4]. The imbalance in the iron availability leads to iron deficiency in most of the CKD patients, especially in stage-5 NDCKD (Non dialytic chronic kidney disease) subjects [5].

Transferrin circulates iron in a soluble, non-toxic form and delivers it to developing reticuloytes in bone marrow and play a key role in iron metabolism. Individual cells modulate their uptake of transferrin-bound iron depending on their iron requirements [6].

Lowered transferrin results from the presence of the Malnutrition-Inflammation-Atherosclerosis syndrome which decreases protein synthesis in the liver. This action is mediated by IL-6 (Interleukin-6), a pro-inflammatory cytokine [7, 8]. Hence it is important to ensure adequate mobilization of tissue iron deposits to increase hemoglobin levels rather than repeatedly administering iron to CKD patients. Recognizing functional iron deficiency and transferrin deficiency is therefore an important concept in the evaluation of anemia in CKD patients.

Soluble transferrin receptor (sTfR) is a product of the transferrin receptor and its concentration in plasma is proportional to the total concentration of cellular TfR. A number of factors may affect the concentration of STfR in plasma or sera: acute or chronic inflammation and the anemias of chronic disease and malnutrition. sTfR may be a good indicator of iron deficiency anemia in iron deficient thalassemia patients and in subjects without inflammation [9, 10]. However, diagnostic accuracy of sTfR as an indicator of iron deficiency anemia is not well established and it may be an appropriate marker for erythropoiesis than iron deficiency [11]. Transferrin saturation and ferritin currently remain better methods for the evaluation of iron status in chronic hemodialysis patients $[12,13]$.

The relationship with iron stores can be seen in the pattern of serum ferritin values under a variety of physiological and pathological conditions. For individual in good health the median level, slightly elevated at birth, reaches a low of about $30 \mathrm{ng} / \mathrm{mL}$, at six months, with the increase to adult levels taking place after puberty. In males, the median level continues to climb- from about $70 \mathrm{ng} / \mathrm{mL}$, at age eighteen to almost $200 \mathrm{ng} / \mathrm{mL}$, twenty-five years later- whereas in females there is a plateau at 35 to $40 \mathrm{ng} / \mathrm{mL}$ throughout the child bearing years and a sharp increase thereafter. For adults in good health, the serum ferritin level has been variously reported to range from $20( \pm 10)$ up to $300( \pm 100) \mathrm{ng} / \mathrm{mL}$ for men and $10( \pm 5)$ up to $150( \pm 50) \mathrm{ng} / \mathrm{mL}$ for women.

\section{Materials and Methods}

This cross-sectional study was carried out in the department of Biochemistry and department of Nephrology, Chittagong Medical College Hospital, Chittagong, Bangladesh from January 2012 to December 2012. Proper permission was taken from the Ethical Committee from Chittagong Medical College.

Total 60 patients of age 18-80 were included in this study. Chronic kidney disease patients with iron deficiency anemia as diagnosed by serum creatinine $>3 \mathrm{mg} / \mathrm{gl}$ and hemoglobin level $<11 \mathrm{~g} / \mathrm{dL}$. and patients who have all the necessary documented investigations were inclusion criteria of the study group. Patients who were suffering from acute kidney disease, age $<18$ years, inadequate data, any malignant condition with CKD, CKD with COPD (chronic obstructive pulmonary disease) and CKD with polycystic kidney disease were excluded from the study group.

\section{Investigations}

There are several reports of diurnal variation of erythropoietin in literature references. It is important to collect 
samples at a consistent time of day. Morning samples taken between 7:30 and 12:00 noon have been recommended. A variation in values may occur if the samples are not clotted at room temperature. Because EDTA (Ethylene diamine tetra acetic acid) would have a significant effect on results, it cannot be used as an anticoagulant. $3 \mathrm{cc}$ bloods was collected from the target subjects by a sterile syringe and labeled it. Then blood was transferred into an epentube. That epentube was then allowed to centrifuge at $3000 \mathrm{rpm}$ for $10 \mathrm{~min}$ and clear supernatant was used for testing.

The following parameters were estimated in the study:

a Serum erythropoietin

b Serum iron

c Serum ferritin

(1) Estimation of serum erythropoietin level by immunometric assay

IMMULITE/IMMULITE 1000 EPO is an acid-phase, enzyme labeled chemiluminescent immunometric assay. The solid phase (bead) is coated with anti-ligand derived from streptavidin. The liquid phase consists of ligand-labeled monoclonal murine anti-EPO antibody and alkaline phosphatase (bovine calf intestine) conjugated to monoclonal murine anti-EPO antibody.

Procedure

The patients sample and the reagent were incubated together with the coated bead for 30 minutes. During this time, EPO in the sample binds to the ligand-labeled monoclonal murine anti-EPO antibody and to the enzyme conjugated murine monoclonal anti-EPO antibody forming a sandwich complex. The immune complex is, in turn, captured by the streptavidin on the bead via the biotinylated anti-EPO antibody. The unbound enzyme conjugate is removed by centrifugal washes. Finally, chemiluminescent substrate is added to the test unit containing the bead and the signal is generated in proportion to the bound enzyme.

Expected values: 5-36 iu (International unit)/L

(2) Estimation of serum iron by clinical chemistry system

Under acidic conditions, iron $\left(\mathrm{Fe}^{3+}\right)$ bound to the protein transferring is released. In the presence of the reducing agent ascorbic acid $\left(\mathrm{Fe}^{3+}\right)$ is reduced to $\left(\mathrm{Fe}^{2+}\right) \cdot\left(\mathrm{Fe}^{2+}\right)$ forms a blue complex with 5.5(3-(2-pyridyl)-1.2.4-triazine -5, 6-diyl)-bis2-furansulfonic acid disodium salt. The absorbance of the complex, measured using a bi-chromatic (600, $700 \mathrm{~nm})$ endpoint technique is directly proportional to the concentration of iron in the serum.

$\mathrm{Fe}^{3+}+$ Transferrin ----- $>\mathrm{Fe}^{3+}+$ Transferrin

$2 \mathrm{Fe}^{3+}+$ Ascorbic acid ----- $>2 \mathrm{Fe}^{2+}+$ di-hydro ascorbic acid $+2 \mathrm{H}^{+}$

$\mathrm{Fe}^{2+}+3$ Ferene------ $>\mathrm{Fe}^{2+}+$ Ferene complex (absorbs at $600 \mathrm{~nm})$

Expected values: $60-150 \mu \mathrm{g} / \mathrm{dL}$.

(3) Estimation of serum ferritin by immunometric assay

IMMILITE/IMMILITE 1000 Ferritin is a solid phase, enzyme labeled chemiluminescent immnometric assay. Antiferritin antibody. The solid phase (bead) is coated with monoclonal murine anti-ferritin antibody. The liquid phase consists of alkaline phosphatase conjugated to polyclonal goat anti-ferritin antibody.

Procedure

The patient sample and the reagent are incubated together with the coated bead for 30 minutes. During this time, ferritin in the sample forms the antibody sandwich complex with monoclonal murine anti-ferritin antibody on the bead and the enzyme conjugated polyclonal goat anti-ferritin antibody in the reagent. Unbound patient sample and enzyme conjugate are then removed by centrifugal washes. Finally, chemiluminescent substrate is added to the test unit containing the bead and the signal is generated in proportion to the bound enzyme.

Expected values: $15-200 \mathrm{ng} / \mathrm{mL}$

\section{Data Analysis}

Data were analyzed by computer based software SPSS v. 18.0 for Windows. Data were expressed as mean $\pm \mathrm{SD}$, and range value. A 'p' value of 0.005 or less was considered for statistical significance.

\section{Results}

Out of 60 patients, 36 patients $(60 \%)$ of the subjects are male. Mean age of the patients were 43.12 years $( \pm 15.14$ SD). Among them $48.4 \%$ were age groups of $21-40$ years. In terms of socio-economic conditions are from average family class. Mean hemoglobin level found $8.67 \mathrm{gm} / \mathrm{dl}$ ( \pm 1.39SD) which is decreased than normal people (Table 1). Serum creatinine level found $8.21 \mathrm{mg} / \mathrm{dl}( \pm 3.25 \mathrm{SD})$ which is higher than normal range (Table 2). Serum iron level found 13.78 $\mu \mathrm{g} / \mathrm{dl}( \pm 2.58 \mathrm{SD})$ which is lower than normal range (Table 3$)$. Results showed mean values of serum erythropoietin were decreased than the reference range. It is found $2.67 \mathrm{miu} / \mathrm{ml}$ $( \pm 2.36 \mathrm{SD})$, which is significantly lower than normal value (Table 4). Serum ferritin level found $73.35 \mathrm{ng} / \mathrm{mL}( \pm$ 26.81SD), which is nearer to normal value (Table 5).

Table 1. Statistics of hemoglobin level among the cases $(n=60)$.

\begin{tabular}{llllll}
\hline \multirow{2}{*}{ Hemoglobin $(\mathrm{gm} / \mathrm{dL})$} & $\mathbf{N}$ & MEAN & SD & MEDIAN & RANGE \\
\cline { 2 - 5 } & 60 & 8.67 & 1.39 & 8.85 & $4.4-11.0$ \\
\hline
\end{tabular}

Table shows $(\mathrm{n}=60)$, mean hemoglobin level is $8.67 \mathrm{gm} / \mathrm{dL}(\mathrm{SD} \pm 1.39)$.

Table 2. Statistics of creatinine level among the cases $(n=60)$.

\begin{tabular}{|c|c|c|c|c|c|}
\hline \multirow{2}{*}{ Serum Creatinine $(\mathrm{mg} / \mathrm{dl})$} & $\mathbf{N}$ & MEAN & SD & MEDIAN & RANGE \\
\hline & 60 & 8.21 & 3.25 & 8.10 & $3.3-15.0$ \\
\hline
\end{tabular}

Table shows $(\mathrm{n}=60)$, mean serum creatinine level of the patient is $8.21 \mathrm{mg} / \mathrm{dL}(\mathrm{SD} \pm 3.25)$ 
Table 3. Statistics of iron level among the cases $(n=60)$.

\begin{tabular}{llllll}
\hline \multirow{2}{*}{ Serum Iron $(\mu \mathrm{g} / \mathrm{dl})$} & N & MEAN & SD & MEDIAN & RANGE \\
\cline { 2 - 6 } & 60 & 13.78 & 2.58 & 14.00 & $10-19$ \\
\hline
\end{tabular}

Table shows ( $\mathrm{n}=60)$, mean serum iron level of the patient is $13.78 \mu \mathrm{g} / \mathrm{dL}(\mathrm{SD} \pm 2.58)$

Table 4. Statistics of erythropoietin level among the cases $(n=60)$.

\begin{tabular}{|c|c|c|c|c|c|}
\hline \multirow{2}{*}{ Serum Erythropoietin $(\mathrm{miu} / \mathrm{mL})$} & $\mathbf{N}$ & MEAN & SD & MEDIAN & RANGE \\
\hline & 60 & 2.67 & 2.36 & 1.35 & $1.0-9.2$ \\
\hline
\end{tabular}

Table shows $(\mathrm{n}=60)$, mean serum erythropoietin level of the patient is $2.67 \mathrm{miu} / \mathrm{mL}(\mathrm{SD} \pm 2.36)$.

Table 5. Statistics of ferritin level among the cases $(n=60)$.

\begin{tabular}{|c|c|c|c|c|c|}
\hline \multirow{2}{*}{ Serum Ferritin (ng/mL) } & $\mathbf{N}$ & MEAN & SD & MEDIAN & RANGE \\
\hline & 60 & 73.35 & 26.81 & 77.00 & $21-138$ \\
\hline
\end{tabular}

Table shows $(\mathrm{n}=60)$, mean serum ferritin level of the patient is $73.35 \mathrm{ng} / \mathrm{mL}(\mathrm{SD} \pm 26.81)$

Table 6. Pearson's correlations between erythropoietin with hemoglobin, iron and ferritin.

\begin{tabular}{lll}
\hline Correlations between & Correlation Coefficient (r) & Significance \\
\hline Erythropoietin \& Hemoglobin & -0.190 & $\mathrm{P}=0.145$ Not Significant \\
Erythropoietin \& Serum Creatinine & -0.082 & $\mathrm{P}=0.532$ Not Significant \\
Erythropoietin \& Serum Iron & 0.021 & $\mathrm{P}=0.872$ Not Significant \\
Erythropoietin \& Serum Ferritin & 0.005 & $\mathrm{P}=0.968$ Not Significant \\
\hline
\end{tabular}

It is also observed that Pearson's correlation coefficient $(\mathrm{r})$ between erythropoietin and hemoglobin is $-0.190(\mathrm{r}=0.036$, $\mathrm{p}$ value $=0.145)$, which is not significant. Correlation coefficient between erythropoietin and creatinine is -0.082 $(\mathrm{r}=0.007 \mathrm{p}$ value $=0.532)$, which is not significant $($ Table 6$)$.

Correlation coefficient between erythropoietin and iron is $0.021(\mathrm{r}=4.549, \mathrm{p}$ value $=0.872)$, which is not significant but shows weakly positive correlation. Correlation coefficient between erythropoietin and ferritin is $0.005(\mathrm{r}=2.723 \mathrm{p}$ value $=0.968$ ) which is not significant but also shows weakly positive correlation.

\section{Discussion}

The aim of this study was designed to measure serum erythropoietin level in CKD patient and observes the relationship among serum erythropoietin and serum iron and serum ferritin.

In this study provides the data of serum erythropoietin level. It is found $2.67 \mathrm{miu} / \mathrm{ml}( \pm 2.36 \mathrm{SD})$ which is significantly lower than normal value. Serum iron level found $13.78 \mu \mathrm{g} / \mathrm{dl}( \pm 2.58 \mathrm{SD})$ which is lower than normal range. Serum ferritin level found $73.35 \mathrm{ng} / \mathrm{mL}$ ( \pm 26.81SD) which is nearer to normal value.

Anemia is defined as a deficiency of red blood cells or hemoglobin in the circulating blood, resulting in reduced oxygenation of body tissue and organs. Normal hematocrit and hemoglobin levels vary according to age, sex, race, among other factors. The World Health Organization (WHO) defines anemia as hemoglobin $<13 \mathrm{~g} / \mathrm{dL}$ for men and postmenopausal women and $<12 \mathrm{~g} / \mathrm{dL}$ for premenopausal women. It is estimated that up to $90 \%$ of patients with chronic renal failure and glomerular filtration rate $<25-30$ $\mathrm{mL} / \mathrm{min}$ will develop anemia. Erythropoietin production is triggered mainly by anemia and tissue hypoxia. In CKD patient, erythropoietin levels are inappropriately low for the degree of anemia. This deficiency results from a progressive loss of nephrons during the natural history of $\mathrm{CKD}$, which limits the production of erythropoietin.

Hypertension is one of the most common problems that can severely harm the kidneys. Uncontrolled high blood pressure is not only the second leading cause of CKD in the United States, but also a symptom of the disease. Sixty-six percent of all patients with CKD are hypertensive. Among African Americans, hypertension is the leading cause of CKD. African Americans develop hypertension more often than Caucasians; they tend to develop it earlier and have more severe forms of the disease [14].

Several observational studies have examined whether achieved $\mathrm{Hb}$ level is associated with all- cause mortality among hemodialysis patients. Madore et al [15] studied a cohort of 21,899 hemodialysis patients and found that a higher baseline $\mathrm{Hb}$ up to a level of $11 \mathrm{~g} / \mathrm{dL}$ was associated with improved survival. Locatelli et al [16] demonstrated that in a cohort of 5302 hemodialysis patients, hematocrit levels $>$ $32 \%$ were associated with lower rates of all cause, cardiovascular and cerebrovascular mortality. In an observational study of 44550 chronic dialysis patients, Ofsthun et al [17] found improved 6 month survival with incremental $\mathrm{Hb}$ levels of up to $12-13 \mathrm{~g} / \mathrm{dL}$. In this study, subjects with $\mathrm{Hb}$ levels $>13 \mathrm{~g} / \mathrm{dL}$ demonstrated similar rates of mortality to those in the $12-13 \mathrm{~g} / \mathrm{dL}$ range.

Kim T et al [18] found that of the 207 patients (125 male), $47(22.7 \%)$ were found to be anemic (males, hemoglobin $(\mathrm{Hb})<12 \mathrm{~g} / \mathrm{dL}$, females $\mathrm{Hb}<11 \mathrm{~g} / \mathrm{dL}$ ). The anemic group had a significantly higher mean serum creatinine level (162.8 $\mu \mathrm{mol} / \mathrm{l}$ vs. $131.0 \mu \mathrm{mol} / \mathrm{l}, \mathrm{p}<0.001)$ and lower mean estimated glomerular filtration rate (eGFR) $(41.5 \mathrm{ml} / \mathrm{min}$ vs. $54.9 \mathrm{ml} / \mathrm{min}, \mathrm{p}<0.001)$ than the non-anemic group. They also found that there was a significant inverse correlation 
between $\mathrm{Hb}$ levels and serum EPO levels $(\mathrm{R}=-0.29$, $\mathrm{p}<$ $0.001)$, but not between EPO levels and eGFR $(\mathrm{R}=0.02, \mathrm{p}=$ 0.74). Suresh $M$ et al [19] found 50 chronic renal failure patient, $\mathrm{RBC}$ count, $\mathrm{Hb}$ concentration, hematocrit and platelet count where significantly $(p=0.0001)$ reduced, whereas total leucocyte count was reduced but not statistically significant $(\mathrm{p}=0.380)$. The serum creatinine level is increased in chronic renal failure patients, which is statistically significant $(\mathrm{p}=0.0001)$.

In term of relationship among serum erythropoietin with serum iron and serum ferritin from my study it also observed that Pearson's correlation coefficient (r) between erythropoietin and hemoglobin is $-0.190(\mathrm{r}=0.036$, $\mathrm{p}$ value $=$ $0.145)$, which is not significant. Correlation coefficient between erythropoietin and creatinine is $-0.082(\mathrm{r}=0.007 \mathrm{p}$ value $=0.532$, which is not significant. Correlation coefficient between erythropoietin and iron is 0.021 ( $r=4.549, \mathrm{p}$ value $=0.872$ ), which is not significant but shows weakly positive correlation. Correlation coefficient between erythropoietin and ferritin is $0.005(\mathrm{r}=2.723 \mathrm{p}$ value $=0.968)$ which is not significant but also shows weakly positive correlation.

In this study it was observed that low erythropoietin level leads to low iron level showing a trend of positive correlation. It was also observed that low erythropoietin level there were nearer to normal ferritin level that may be due to repeated blood transfusion and other physiological phenomenon to compensate blood anemia. It was also observed that socioeconomic condition affects indirectly on CKD that may be due to hypertension, diabetes mellitus or other multifactorial causes

\section{Conclusion}

The risk of death in patients with advanced chronic kidney disease (CKD) is markedly higher than in the population without CKD, even in patients suffering from advanced cardiovascular disease. Among several clinical features of CKD, the following are considered the most important areas of therapeutic intervention: hypertension, lipid abnormalities, mineral and bone disorders of CKD (previously known as renal osteodystrophy), renal anemia, and uremic toxicity.

Chronic kidney disease (CKD) affects millions of people worldwide, with high incidence and prevalence and increasing costs. Anemia, a common observation in CKD, can develop in the early phases of the disease and contributes to a poor quality of life [20]. Anemia in patients with CKD is due to many factors. Erythropoiesis and iron homeostasis are impaired as a result of a complex chain of events, including the relative deficiency of erythropoietin, chronic inflammation, blood loss, decreased iron absorption and utilization, exogenous iron and erythropoietin acquisition via biologically unregulated mechanisms (blood transfusions and medicinal erythropoietin and iron administration) $[21,22]$.

Anemia is present in the majority of the chronic kidney disease patients. It is associated with a number of physiologic abnormalities, including decreased tissue oxygen delivery and utilization, increased cardiac output, cardiac hypertrophy, angina, congestive cardiac failure and mental acuity, altered menstrual cycles and impaired immune responsiveness. These abnormalities reduce quality of life and opportunities for rehabilitation of CKD patients and decrease patient survival.

From the present study it can be concluded that patients with chronic renal failure show abnormal hematological parameters. It has shown that in chronic kidney disease patients, impaired production of erythropoietin is the main reason for the decrease in hemoglobin concentration and also other blood cells. Other associated factors like increase hemolysis, suppression of bone marrow erythropoiesis, hematuria and gastrointestinal blood loss may play a role in decrease red blood cell count, hemoglobin percentage and hematocrit.

The most effective way to reduce the burden of CKD is to prevent and treat its risk factors. Screening individuals at high risk for CKD (e.g. people older than 50 years, people with a history of diabetes mellitus, hypertension, cardiovascular disease, or people who have a family history of CKD) may prevent or delay kidney failure. Screening demonstration projects are currently ongoing to evaluate the effectiveness. Therapeutic treatments can slow progression of kidney disease as well as manage its complications. Timely referral to a nephrologists and getting treatment also improves outcomes.

Disclosure: All the authors declared no competing interest.

\section{References}

[1] Centers for Disease Control and Prevention (CDC). (2011). National diabetes fact sheet. Retrieved from www.cdc.gov/diabetes/pubs/pdf/ndfs_2011.pdf

[2] United States Renal Data System (USRDS). (2010). Annual data report. Retrieved from www.usrds.org/2012/pdf

[3] Eschbach J, Adamson J. Recombinant human erythropoietin; Implications for nephrology, Am J Kidney Dis 1988; 11; 203-9

[4] Lipschitz D, et al, A clinical evaluation of serum ferritin as an index of iron stores. N Engl J Med 1974; 290: 1213-16

[5] Fishbane S. Iron supplementation in renal anemia. Semin Nephrol 2006; 26(4): 319-324

[6] Frazer DM, Anderson GJ. The regulation of iron transport. Biofactors 2013

[7] Kalantar-Zadeh K, Regidor DL, McAllister CJ, Michael B, Warnock DG. Time-dependent associations between iron and mortality in hemodialysis patients. J Am Soc Nephrol 2005; 16(10): 3070-3080

[8] Balla J, Jeney V, Varga Z, Komodi E, Nagy E, Balla G. Iron homeostasis in chronic inflammation. Acta Physiol Hung 2007; 94(1-2): 95-106

[9] Khatami S, Dehnabeh SR, Mostafavi E, Kamalzadeh N, Yaghmaei P, Saeedi P, Shariat F, Bagheriyan H, Zeinali S, Akbari MT. Evaluation and comparison of soluble transferrin receptor in thalassemia carriers and iron deficient patients. Hemoglobin 2013; 37(4): 387-395 
[10] Engle-Stone R, Nankap M, Ndjebayi AO, Erhardt JG, Brown $\mathrm{KH}$. Plasma ferritin and soluble transferrin receptor concentrations and body iron stores identify similar risk factors for iron deficiency but result in different estimates of the national prevalence of iron deficiency and iron-deficiency anemia among women and children in Cameroon. J Nutr 2013; 143(3): 369-377

[11] Infusino I, Braga F, Dolci A, Panteghini M. Soluble transferrin receptor (sTfR) and sTfR/log ferritin index for the diagnosis of iron-deficiency anemia. A meta-analysis. Am J Clin Pathol 2012; 138(5): 642-649

[12] van der Weerd NC, Grooteman MP, Bots ML, van den Dorpel MA, den Hoedt $\mathrm{CH}$, Mazairac AH, Nube MJ, Penne EL, Gaillard CA, Wetzels JF, Wiegerinck ET, Swinkels DW, Blankestijn PJ, Ter Wee PM. Hepcidin-25 in chronic hemodialysis patients is related to residual kidney function and not to treatment with erythropoiesis stimulating agents. PLoS One 2012; 7(7): e39783

[13] Chiang WC, Tsai TJ, Chen YM, Lin SL, Hsieh BS. Serum soluble transferrin receptor reflects erythropoiesis but not iron availability in erythropoietin-treated chronic hemodialysis patients. Clin Nephrol 2002; 58(5): 363-369

[14] American Society of Hypertension. (2011). Welcome. Retrieved from www.ash-us.org

[15] Madore F, Lowrie EG, Brugnara C, et al. Anemia in hemodialysis patients: variables affecting this outcome predictor. J AM Soc Nephrol. 1997; 8(12):1921-1929

[16] Locatelli F, Conte F, Marcelli D. The impact of haematocrit levels and erythropoietin treatment on overall and cardiovascular mortality and morbidity- the experience of the
Lombardy Dialysis Registry. Nephrol Dial Transplant. 1998; 13(7): 1642-1644

[17] Ofsthun N, Labrecque J, Lacson E, Keen M, Lazarus M. The effects of higher hemoglobin levels on mortality and hospitalization in hemodialysis patients. Kidney Int. 2003; 63(5): 1908-1914

[18] Kim T Sinnamon, Aisling E. Courtney, A. Peter Maxwell, Peter T. McNamee, Geraldine Savage and Damian G. Fogarty. Level of renal function and serum erythropoietin levels independently predict anemia post renal transplantation. Nephrol Dial Transplant (2007) 22: 1969-1973

[19] Suresh M, Mallikarjuna reddy N, Sharan B Singh M, Hari Krisna Bandi, Shravya Keerthi G, Chandrasekhar M. Hematological Changes in Chronic Renal Failure. International Journal of Scientific and Research Publications, Volume 2, Issue 9, September 2012

[20] Garabed Eknoyn, Norbert Lameire, Rashad Barsoum, KaiUwe Eckardt, Adeera Levin, Nathan Levin, Francesco Locatelli, Alison Macleod, Raymond Vanholder, Rowan Walker and Haiyan Wang. The burden of kidney disease: Improving global outcomes. Kidney International 66(2004), pp 1310-1314

[21] G. Weiss, I. Theuri, S. Eder, C. Koppelstaetter, K. Kurn, T. Sonnweber, U. Kobold, G. Mayer. Serum hepticidin concentration in chronic haemodialysis patients; associations and effects of dialysis, iron and erythropoietin therapy. Eur J clin Invest 2009; 39(10); 883-890

[22] Gian Cesare Guidi, Clara Lechi Santonastaso. Advancements in anemias related to chronic conditions. Clinical Chemistry and Laboratory Medicine vol.48, issue 9, page 1217-1226, July 2010 